Proceedings

\title{
Effects of Transport Inhibitors on the Internalization of Cellular Vesicles by Different Breast Cancer Cell Lines ${ }^{\dagger}$
}

\author{
Paraskevi Sotiropoulou ${ }^{1,2}, *$, Antonia Marazioti ${ }^{1}$ and Sophia G. Antimisiaris ${ }^{1,2}$ \\ 1 Laboratory of Pharmaceutical Technology, Department of Pharmacy, University of Patras, \\ Rio 26510 Patras, Greece; amarazioti@upatras.gr (A.M.); santimis@upatras.gr (S.G.A.) \\ 2 Institute of Chemical Engineering, FORTH/ICE-HT, Rio 26504 Patras, Greece \\ * Correspondence: up1020509@upnet.gr; Tel.: +30-697-153-0541 \\ + Presented at the 1st International Electronic Conference on Pharmaceutics, 1-15 December 2020; \\ Available online: https://iecp2020.sciforum.net/.
}

Citation: Sotiropoulou, P.;

Marazioti, A.; Antimisiaris, S.G. Effects of Transport Inhibitors on the Internalization of Cellular Vesicles by Different Breast Cancer Cell Lines. Proceedings 2021, 78, 48. https://doi.org/10.3390/IECP2020-086 47

Published: 1 December 2020

Publisher's Note: MDPI stays neutral with regard to jurisdictional claims in published maps and institutional affiliations.

Copyright: $₫ 2020$ by the authors. Licensee MDPI, Basel, Switzerland. This article is an open access article distributed under the terms and conditions of the Creative Commons Attribution (CC BY) license (http://creativecommons.org/licenses /by/4.0/).

\begin{abstract}
Liposomes are spherical vesicles composed of natural or artificial lipids and are used as drug carriers. However, their surface needs modification with ligands to target specific tissues. Cell-derived vesicles (CVs) are bioinspired drug carriers, as they are derived from cells by physical methods. Therefore, they preserve the topology and composition of the molecules present in the plasma membrane of the parental cell, enabling in vivo organotropism and specific drug delivery. The aim of this study is the investigation of the mechanisms by which liposomes and autologous $\mathrm{CVs}$ are internalized by three different breast cancer cell lines. The elucidation of the mechanism is likely to result in their optimization as drug carriers and the comprehension of their sub-cellular fate. More specifically, liposomes and CVs were produced, characterized, and loaded with the fluorescent dye FITC-dextran. Uptake experiments were performed using inhibitors of the clathrin-dependent or caveolin-dependent endocytic pathways and after incubating the cells at $4{ }^{\circ} \mathrm{C}$, where energy dependent processes are inactivated. The results indicate that the endocytosis of $\mathrm{CVs}$ is active, mainly via the caveolin pathway, whereas liposomes are internalized actively by both pathways and also passively, as their uptake at $4{ }^{\circ} \mathrm{C}$ is not significantly hampered.
\end{abstract}

Keywords: liposomes; cellular vesicles; breast cancer

\section{Introduction}

Liposomes are spherical vesicles that have been increasingly used for biomedical and biotechnological purposes over the past years as a result of their drug delivery capacity. They consist of natural or artificial lipids that form at least one bilayer, which surrounds an aqueous solution core. Liposomes are used as drug carriers due to their numerous advantages. They are biocompatible and biodegradable; they can carry hydrophilic, lipophilic and amphiphilic molecules; and their production is simple. However, they do not exhibit specific drug delivery unless their surface is modified with the appropriate ligands [1].

Cell-derived vesicles (CVs) are bioinspired drug carriers, as they are derived from whole cells by physical means, such as extrusion. Their most striking characteristic is their ability to retain the composition of the plasma membrane of their parental cells, leading to in vivo organotropism and targeting of specific tissues. As they have a physical origin, there are no concerns regarding their biocompatibility and biodegradability [2]. CVs have been used as carriers for anticancer drugs in order to deliver the substance directly to the cancer cells, reinforcing their action and limiting their side effects [3].

The purpose of this study is the investigation of the mechanisms by which liposomes and autologous CVs are internalized by three different breast cancer cell lines. Two of the selected cell lines, 4T1 (mouse) and MDA-MB-231 (human), are triple nega- 
tive breast cancer cell lines, and the third one, MCF-7 (human), is negative only for the protein HER2. It is essential to understand the mechanisms of endocytosis of drug carriers in order to improve their efficacy and determine their sub-cellular fate and localization [4].

Liposomes and CVs were produced, physicochemically characterized, and were loaded with the fluorescent dye FITC-dextran. The uptake of the particles was studied using inhibitors of the clathrin-dependent and caveolin-dependent endocytic pathways, chlorpromazine and filipin, respectively. The cells were also incubated at $4{ }^{\circ} \mathrm{C}$ to inactivate the active processes and examine whether the particles are internalized passively. The results of the uptake experiments show that the endocytosis of the autologous CVs is an active process, mainly via the caveolin pathway. Liposomes are internalized actively by both pathways but also passively.

\section{Experiments}

\subsection{Cell Lines and Culture Conditions}

4T1, MDA-MB-231 and MCF-7 cell lines were routinely grown in RPMI 1640 Medium (Gibco, ThermoFischer Scientific, Greece), supplemented with 10\% fetal bovine serum and $1 \%$ antibiotic penicillin/streptomycin at $37{ }^{\circ} \mathrm{C}$ in $5 \% \mathrm{CO}_{2}$. When confluent, cells were washed with PBS and treated with Trypsin $0.25 \%$ (Biowest) for seeding in new culture flasks.

\subsection{Liposome Preparation}

1,2-distearoyl-sn-glycerol-3-phosphatidylcholine (PC), 1,2-distearoyl-sn-glycero-3phospho-(1'-rac-glycerol) (sodium salt) (PG) and cholesterol (CHOL), in a proportion of PC/PG/CHOL 9:1:5 (molar) formed liposomes by the thin film hydration method in 10\% PBS. Next, samples were probe sonicated (Sonics Vibra Cell, Sonics \& Materials, Leics, UK), centrifuged, and annealed at $40^{\circ} \mathrm{C}$ in a water bath for $1 \mathrm{~h}$. Lipid concentration was measured by Stewart assay [5].

\subsection{Cellular Vesicles Isolation}

For CV isolation, cells were cultured until full confluency, detached with trypsin, centrifuged, and washed $\times 3$ with PBS and were resuspended in water. CVs were obtained by ultracentrifugation (Thermo Sorvall WX90 Ultra, Thermo Scientific, Waltham, MA, USA) for $2 \mathrm{~h}$ at $60,000 \mathrm{rpm}$ and $4{ }^{\circ} \mathrm{C}$, and were resuspended in $10 \%$ PBS. Finally, CVs were extruded through polycarbonate membranes of 400 and $200 \mathrm{~nm}$ pore size (Whatman, GE Healthcare Life Sciences, Life Science Chemilab, Greece). Protein concentration was measured by Bradford assay (Biorad, Hercules, CA, USA), and lipid concentration by the Stewart method [5].

\subsection{FITC Loading}

FITC-dextran $36 \mathrm{mM}$ was mixed in the liposome or $\mathrm{CV}$ dispersion. The mixture was freeze-dried; rehydrated; and, after ultracentrifugation for $2 \mathrm{~h}$ at $60.000 \mathrm{rpm}$ and $4{ }^{\circ} \mathrm{C}$, the pellet was resuspended in PBS. Finally, the samples were extruded through polycarbonate membranes of 400 and $200 \mathrm{~nm}$ pore size.

\subsection{Physicochemical Characterization}

The particle size distribution (mean hydrodynamic diameter and polydispersity index) of liposomes and CVs in PBS, pH $7.4(10 \mathrm{mM})$, was measured by dynamic light scattering (DLS) (Malvern Nano-Zs, Malvern Instruments, Malvern, UK) at $25{ }^{\circ} \mathrm{C}$. $\zeta$-potential was measured with the same dispersions and conditions. 


\subsection{Uptake Experiments}

Cells $\left(1 \times 10^{5} \mathrm{cells} / \mathrm{mL}\right)$ were plated in 6-well-plates. The next day, 2 of the wells were used as a control, 2 of them were pre-incubated for $30 \mathrm{~min}$ with chlorpromazine $10 \mu \mathrm{g} / \mathrm{mL}$, and 2 of them were pre-incubated for $30 \mathrm{~min}$ with filipin $5 \mu \mathrm{g} / \mathrm{mL}$. Another 6-well plate was pre-incubated at $4{ }^{\circ} \mathrm{C}$ for $30 \mathrm{~min}$. After this pre-incubation time, an aliquot of the FITC-dextran loaded samples was added to each well, and the plates were incubated for $2 \mathrm{~h}$ either in the presence of the liposomes or the $\mathrm{CVs}$ at $37^{\circ} \mathrm{C}$ or at $4{ }^{\circ} \mathrm{C}$, respectively. Then, wells were washed three times with PBS and the cells were lysed with Triton 20\% and collected with a cell scraper. FITC uptake was measured by spectrofluorophotometry (Shimadzu RF-5301 PC, Tokyo, Japan), with excitation at $490 \mathrm{~nm}$ and emission at $520 \mathrm{~nm}$, and protein concentration was measured by Bradford assay (Biorad, Hercules, CA, USA).

\section{Results}

\subsection{Physicochemical Characterization}

The liposomes and CVs were characterized as described above using DLS. Table 1 shows the results of the size distribution, polydispersity index (PDI), and $\zeta$-potential. The protein to lipid ratio of the CVs is also reported.

Table 1. Physicochemical characterization of liposomes and CVs.

\begin{tabular}{ccccc}
\hline & Size $(\mathbf{n m})$ & PDI & $\zeta$-Potential $(\mathbf{m V})$ & Protein/Lipid \\
\hline PC/PG/CHOL & $74.59 \pm 0.50$ & $0.234 \pm 0.015$ & $-14.2 \pm 0.84$ & - \\
4T1-CVs & $249.2 \pm 2.80$ & $0.347 \pm 0.032$ & $-14.2 \pm 0.85$ & 0.39 \\
MDA-MB-231-CVs & $289.5 \pm 8.29$ & $0.386 \pm 0.024$ & $-15.0 \pm 0.56$ & 0.34 \\
MCF-7-CVs & $253.4 \pm 6.50$ & $0.382 \pm 0.036$ & $-14.8 \pm 1.36$ & 0.31 \\
\hline
\end{tabular}

\subsection{Uptake Experiments}

\subsubsection{Uptake of Liposomes}

The mechanism of endocytosis of negatively charged liposomes in the breast cancer cell lines was investigated by incubating the cells either at $37^{\circ} \mathrm{C}$ in the presence of the transport inhibitors chlorpromazine and filipin, or at $4{ }^{\circ} \mathrm{C}$. Figure 1 describes the uptake normalized to the cell protein concentration in the three different breast cancer cell lines. When the cells were treated with the inhibitors of the clathrin-dependent or caveolin-dependent endocytic pathways, the uptake per protein was significantly lower than that of the control. Therefore, liposomes were internalized actively by both pathways. However, when active processes were inactivated (at $\left.4{ }^{\circ} \mathrm{C}\right)$, the uptake was not significantly hampered, indicating that passive internalization also occurs.

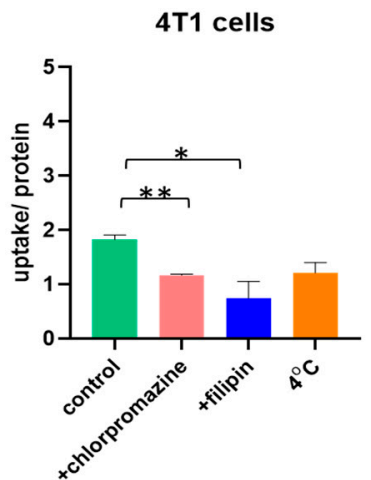

(a)

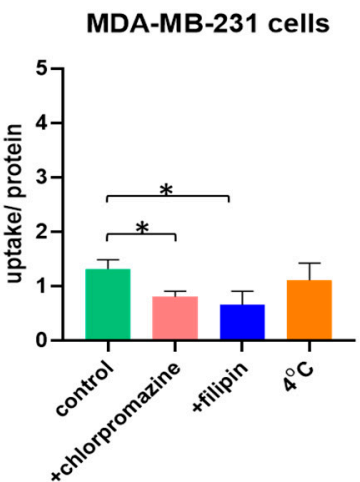

(b)

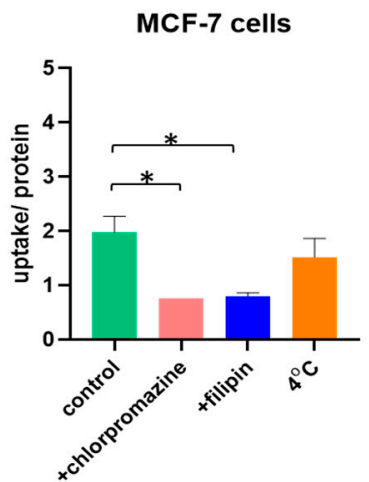

(c)

Figure 1. Uptake of PC/PG/CHOL 9:1:5 liposomes in different breast cancer cell lines in the presence of transport inhibitors or at $4{ }^{\circ} \mathrm{C}$ (normalized to cell protein). (a) Uptake per protein of liposomes in $4 \mathrm{~T} 1$ cells; (b) uptake per protein of liposomes in MDA-MB-231 cells; (c) uptake per protein of liposomes in MCF-7 cells. ${ }^{*} p<0.05,{ }^{* *} p<0.01$. 


\subsubsection{Uptake of CVs}

The uptake of CVs isolated from the three breast cancer cell lines mentioned above was studied under the same conditions as the liposomes. Figure 2 shows the effect of the transport inhibitors chlorpromazine and filipin on the uptake normalized to the cell protein concentration of the autologous CVs.

4T1-CVs-4T1 cells

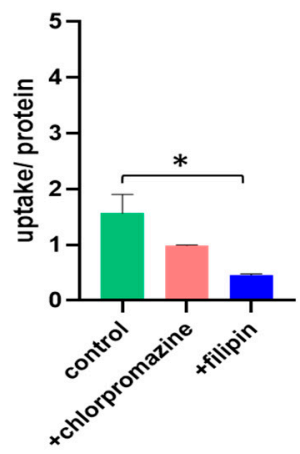

(a)
MDA-MB-231-CVs- MDA-MB-231 cells

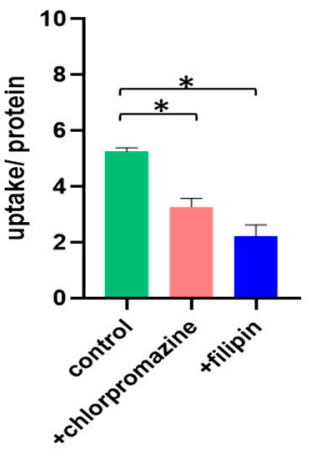

(b)

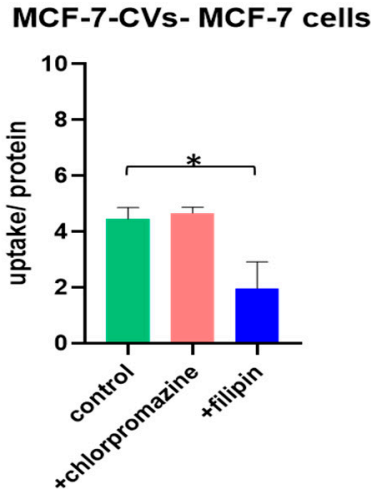

(c)

Figure 2. Uptake of autologous CVs in the breast cancer cell lines in the presence of transport inhibitors (normalized to cell protein). (a) Uptake per protein of 4T1-CVs in 4T1 cells; (b) uptake per protein of MDA-MB-231-CVs in MDA-MB-231 cells; (c) uptake per protein of MCF-7-CVs in MCF-7 cells. ${ }^{*} p<0.05$.

The uptake per protein of 4T1-CVs was significantly lower in the presence of filipin, suggesting that the endocytosis is realized via the caveolin-dependent pathway. In the presence of chlorpromazine, the uptake was lower than that of the control, although the reduction was not statistically significant. When the MDA-MB-231 cells were treated with the transport inhibitors, the uptake of MDA-MB-231-CVs was significantly hampered. Consequently, MDA-MB-231-CVs are internalized by both the clathrin-dependent and caveolin-dependent pathways. Finally, the uptake of MCF-7-CVs was significantly lower only in the presence of filipin, indicating internalization by the caveolin-dependent pathway. In the presence of chlorpromazine, the uptake was similar to that of the control. The uptake of CVs at $4{ }^{\circ} \mathrm{C}$ is currently under evaluation.

\section{Discussion}

Liposomes are used widely as drug carriers, and CVs are promising carriers that can target specific organs or cells. In order to use them more effectively, it is necessary to understand the distinct endocytic mechanisms by which they enter the target cells. This first step can lead to the optimization of specific drug delivery and determine their ultimate sub-cellular fate and localization. In this study, the endocytic mechanisms of negatively charged liposomes and autologous CVs produced by three different breast cancer cell lines were investigated.

The uptake of liposomes in all selected cell lines was significantly hampered in the presence of both chlorpromazine and filipin, which means that their endocytosis is realized via the clathrin-dependent and caveolin-dependent pathways. However, at $4{ }^{\circ} \mathrm{C}$, their uptake was not affected significantly compared to the control, suggesting that a passive endocytic mechanism is also present.

The uptake of 4T1-CVs and MCF-7-CVs seemed to be affected only in the presence of filipin, assuming that their internalization is active via the caveolin-dependent pathway. MDA-MB-231-CVs are also internalized actively, but their uptake was significantly lower in the presence of both transport inhibitors. 


\section{Conclusions}

This research gives insight into the endocytic mechanisms used by liposomes and autologous CVs to enter 4T1, MDA-MB-231, and MCF-7 cells. It can be concluded that liposomes are internalized both actively, by the clathrin-dependent and caveolin-dependent pathways, and passively. CVs are internalized mainly actively by the caveolin-dependent pathway.

Author Contributions: S.G.A. and A.M. conceived and designed the experiments; P.S. and A.M. performed the experiments; P.S. and A.M. analyzed the data; P.S., A.M. and S.G.A. wrote/edited the paper. All authors have read and agreed to the published version of the manuscript.

Institutional Review Board Statement: Not applicable.

Informed Consent Statement: Not applicable.

Data Availability Statement: The data presented in this study are available in the results section of the article.

Acknowledgments: This research has been co-financed by the European Regional Development Fund of the European Union and Greek national funds through the Operational Program Competitiveness, Entrepreneurship and Innovation, under the call RESEARCH-CREATE-INNOVATE (project code: MIS 5031802).

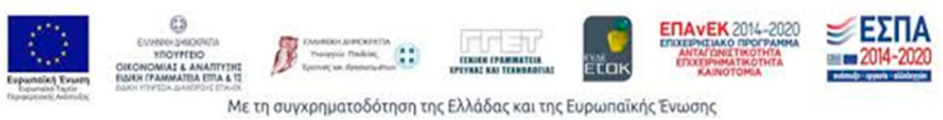

Conflicts of Interest: The authors declare no conflict of interest. The founding sponsors had no role in the design of the study; in the collection, analyses, or interpretation of data; in the writing of the manuscript, and in the decision to publish the results.

\section{Abbreviations}

The following abbreviations are used in this manuscript:

$\begin{array}{ll}\text { CVs } & \text { Cellular vesicles } \\ \text { PC } & \text { 1,2-distearoyl-sn-glycerol-3-phosphatidylcholine } \\ \text { PG } & \text { 1,2-distearoyl-sn-glycero-3-phospho-(1'-rac-glycerol) } \\ \text { CHOL } & \text { Cholesterol } \\ \text { DLS } & \text { Dynamic light scattering } \\ \text { PDI } & \text { Polydispersity index }\end{array}$

\section{References}

1. Antimisiaris, S.G.; Kallinteri, P.; Fatouros, D.G. Liposomes and Drug Delivery. Pharm. Sci. Encycl. Drug Discov. Dev. Manuf. 2010, 1-91, doi:10.1002/9780470571224.pse352.

2. Goh, W.J.; Zou, S.; Ong, W.Y.; Torta, F.; Alexandra, A.F.; Schiffelers, R.M.; Storm, G.; Wang, J.W.; Czarny, B.; Pastorin, G. Bioinspired Cell-Derived Nanovesicles versus Exosomes as Drug Delivery Systems: A Cost-Effective Alternative. Sci. Rep. 2017, 7 , 14322, doi:10.1038/s41598-017-14725-x.

3. Goh, W.J.; Lee, C.K.; Zou, S.; Woon, E.C.; Czarny, B.; Pastorin, G. Doxorubicin-loaded cell-derived nanovesicles: An alternative targeted approach for anti-tumor therapy. Int. J. Nanomed. 2017, 12, 2759-2767, doi:10.2147/IJN.S131786.

4. dos Santos, T.; Varela, J.; Lynch, I.; Salvati, A.; Dawson, K. Effects of Transport Inhibitors on the Cellular Uptake of Carboxylated Polystyrene Nanoparticles in Different Cell Lines. PLoS ONE 2011, 6, e24438, doi:10.1371/journal.pone.0024438.

5. Stewart, J.C.M. Colorimetric determination of phospholipids with ammonium ferrothiocyanate. Anal. Biochem. 1980, 104, 10-14, doi:10.1016/0003-2697(80)90269-9. 